UDP-glucuronosyltransferase purified to apparent homogeneity is not merely an artifact due to the isolation procedure but reflects the enzyme defect in vivo.

Acknowledgements-We wish to thank Miss S. Zachmann and Mr. I. Duffy for excellent technical assistance. We also thank the Medical Research Council and the Deutsche Forschungsgemeinschaft for grants supporting this work. B.B. is currently the recipient of a Wellcome Special Research Leave Fellowship.

Department of Biochemistry,

BRIAN BURCHELL

Medical Sciences Institute,

The University,

Dundee DD1 $4 M N$,

Scotland

Department of Pharmacology and Toxicology,

University of Göttingen,

D-3400 Göttingen,

Federal Republic of Germany

\section{REFERENCES}

1. G. J. Dutton and B. Burchell, Prog. Drug. Metab. 2, 1 (1977).

2. C. H. Gunn, J. Hered. 29, 137 (1938).

3. G. A. Lathe and M. Walker, Biochem. J. 67, 9P (1957).

4. J. Carbone and G. M. Grodsky, Proc. Soc. exp. biol. Med. 94, 449 (1957).

5. R. Schmid, J. Axelrod, L. Hammaker and R. L. Swarm, J. clin. Invest. 37, 1123 (1958).

6. I. M. Arias, Biochem. biophys. Res. Commun. 6, 81 (1961).
7. I. H. Stevenson, D. Greenwood and J. McEwan, Biochem. biophys. Res. Commun. 32, 866 (1968).

8. El-N. M. A. Lalani and B. Burchell, Biochem. J. 177, 993 (1979).

9. El-N. M. A. Lalani, P. J. Weatherill, S. M. E. Kennedy and B. Burchell, Biochem. Pharmac. 29, 2367 (1980).

10. A. Winsnes and G. J. Dutton, Biochem. Pharmac. 22, 1 (1973).

11. P. J. Weatherill and B. Burchell, Fedn. Eur. biochem. Soc. Lett. 87, 207 (1978).

12. W. Heubner, Arch. Exp. Path. Pharmak. 72, 241 (1913).

13. G. A. Levvy, A. McAllan and C. A. March, Biochem. J. 69, 22 (1958).

14. A. Winsnes, Biochim. biophys. Acta 191, 279 (1969).

15. M. M. Bradford, Analyt. Biochem. 72, 255 (1976).

16. K. W. Bock and I. N. H. White, Eur. J. Biochem. 46, 451 (1974).

17. K. W. Bock, U. C. V. Clausbruch and H. Ottenwälder, Biochem. Pharmac. 27, 369 (1978).

18. G. A. Levvy and I. D. E. Storey, Biochem. J. 44, 295 (1949).

19. H. P. A. Illing and G. J. Dutton, Biochem. J. 129, 539 (1972).

20. G. Otani, M. M. Abou-El-Makarem and K. W. Bock, Biochem. Pharmac. 25, 1293 (1976).

21. K. W. Bock, W. Frohling and H. Remmer, Biochem. Pharmac. 22, 1557 (1973).

22. R. E. McMahon, Handbook of Experimental Pharmacology Edited by B. B. Brodie and J. R. Gillette Vol. 28. (part 2), p. 500 (1971). Springer-Verlag, Berlin, Heidelberg, New York.

23. R. L. Felsted, M. Gee and N. R. Bachur, J. biol. Chem, 249, 3672 (1974)

24. B. Burchell, Biochem. J. 173, 749 (1978).

25. K. W. Bock, D. Josting, W. Lilienblum and H. Pfeil, Eur. J. Biochem. 98, 19 (1979).

\title{
Inhibition of hepatic lipid biosynthesis by 1-(3-chlorophenyl)-1-methyl-2-phenyl-2- (2-pyridine) ethanol, a hypocholesterolemic agent
}

(Received 21 January 1980; accepted 17 June 1980)

A large number of derivatives of generic structure I [2-(2pyridine)-1,2-diarylalkanols] were prepared by Burckhalter et al. [1] as potential hypocholesterolemic agents having minimal estrogenicity.

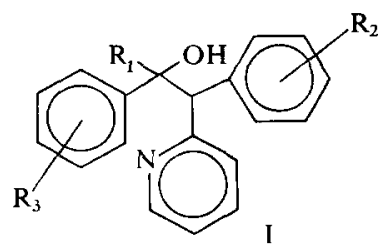

Several of the compounds exhibited significant serum cholesterol-lowering activity in rats with only slight estrogenic effect. Compound $1\left(\mathrm{R}_{1}=\mathrm{CH}_{3}, \mathrm{R}_{2}=\mathbf{H}\right.$, and $\mathbf{R}_{3}=$ $m$-Cl) [1-(3-chlorophenyl)-1-methyl-2-phenyl-2-(2-pyridine) ethanol] was selected from a series of the 133 derivatives for study of its hypocholesterolemic effect in humans. Although the compound was non-toxic and was found to lower serum cholesterol levels in rats, it had no hypocho- lesterolemic effect in humans or in monkeys [1]. To understand why compound 1 was active in rats, the present investigation was initiated. The results suggest that this compound, or a metabolite(s), lowers serum cholesterol levels by inhibiting hepatic lipid biosynthesis.

Male Sprague--Dawley rats weighing $150-180 \mathrm{~g}$ were used for all experiments. Rats were housed two per cage, with Purina Rat Chow and water available ad lib. Compound 1 was suspended in $0.5 \%(\mathrm{w} / \mathrm{v})$ sodium carboxy methyl cellulose (CMC) by mixing in a glass mortar. The suspension was administered to experimental animals (four or five rats) at $25 \mathrm{mg} \cdot \mathrm{kg}^{-1} \cdot \mathrm{day}^{-1}$ by gastric intubation once a day in the morning for 4 days. Control animals (four or five rats) received equivalent volumes of $0.5 \% \mathrm{CMC}$. Animals were weighed daily. On the morning of day $5,\left[2-{ }^{14} \mathrm{C}\right]$ acetate $(10 \mu \mathrm{Ci} / 100 \mathrm{~g}$ body wt in $0.5 \mathrm{ml}$ saline) was injected intraperitioneally into both control and experimental animals. Exactly $1 \mathrm{hr}$ after the injection of radioactive precursor, blood was collected by cardiac puncture into a test tube containing heparin sodium (100 units). Animals were under light ether anesthesia. The livers were then removed, washed twice with ice-cold saline, and homogenized in 
2 vol. of isotonic $\mathrm{KCl}$ with a Super Dispax Tissumizer (Tekmar, Cincinnati, $\mathrm{OH}$ ).

Total plasma cholesterol levels were determined using the method of Franey and Amador [2]. Lipids of hoth liver and blood plasma were extracted with $\mathrm{CHCl}_{3}-\mathrm{MeOH}(2: 1$, $\mathrm{v} / \mathrm{v})$, followed by a washing procedure with saline according to the method of Folch et al. [3]. The crude lipid extract was then fractionated into each lipid class by thin-layer chromatography using silica gel $\mathbf{G}$ or $\mathbf{H}$ plates (Prekotes, Applied Science Laboratories, State College, PA). Plates were developed with a system of either hexane-diethyl ether-acetic acid $(90: 10: 1$, by vol.) [4] or isopropyl etheracetic acid $(96: 4, \mathrm{v} / \mathrm{v})$, followed by light petroleum-ethyl ether-acetic acid ( $90: 10: 1$, by vol.) [5]. Lipid bands on the plate were detected by iodine vapor and scraped from the plate after brown colors had faded. Silica gel was extracted three times with either $\mathrm{CHCl}_{3}-\mathrm{MeOH}, 2: 1$ (for neutral lipids) or $\mathrm{CHCl}_{3}-\mathrm{MeOH}$-acetic acid-water, $50: 39: 1: 10$ (for phospholipids). After cvaporation of the solvents, frec and esterified cholesterol ( $\mathrm{Ch}$ and $\mathrm{ChE}$ ), triglyceride (TG), free fatty acids (FFA) and phospholipid (PL) were determined with slight modifications using the methods of Franey and Amador [2], Hanahan and Olley [6], Duncombe [7] and Rouser et al. [8] respectively. Radioactivity was determined in a Beckman model LS 200 liquid scintillation spectrometer using $15 \mathrm{ml}$ of toluene-EtOH, 7:3(v/v) with $0.4 \%(w / v)$ PPO and $0.01 \%(w / v)$ POPOP for lipid soluble materials. ${ }^{*}$ Recovery of label from thin-layer plates ranged from 84 to 92 per cent. To determine the radioactivity in whole liver homogenates or blood plasma, $0.1 \mathrm{ml}$ of each was solubilized in $10 \mathrm{ml}$ Protosol (New England Nuclear, Boston, MA) by standing at ambient temperature overnight and then counting in the toluene-EtOH scintillation fluid described above. Counting efficiency in all studies was determined by the external standard method. Statistical significance of results was estimated by Student's $t$-test.

Animals treated with $25 \mathrm{mg} \cdot \mathrm{kg}^{-1} \cdot \mathrm{day}^{-1}$ of compound 1 for 4 days showed the expected $[1,9]$ decrease in plasma total cholesterol concentrations. In these experiments, levels declined to 74 per cent of control values (Table 1). The animals also. showed a very slight decline in body weight gain (Table 1).

The incorporation of $\left[{ }^{14} \mathrm{C}\right]$ acetate into plasma and liver also was measured in these experiments. Labeled acetate was injected intraperitoneally $1 \mathrm{hr}$ before the animals were killed and $24 \mathrm{hr}$ after the final dose of compound 1. As shown in Table 1 , there was no significant difference between the two groups of animals in carbon-14 labeling

* PPO = 2,5-diphenyloxazole; POPOP $=1,4$-bis-[2-(4methyl-5-phenyloxazolyl)]benzene. of either liver homogenate or blood plasma. These results indicate that neither uptake by liver nor distribution of injected $\left[{ }^{14} \mathrm{C}\right]$ acetate was affected by the pretreatment of rats with compound 1 .

In contrast, the radioactivity detected in the total lipid extract of the plasma and liver specimens was much lower in the compound 1-treated group than in the control group of rats (Table 2). In plasma, radioactivity in the total lipid extract represented $3.6 \pm 0.8$ per cent of the radioactivity in unfractionated plasma from control animals, but was reduced to $2.5 \pm 0.7$ per cent in treated animals $(\mathrm{P}<0.05)$. Similarly, the fraction of $\left[{ }^{14} \mathrm{C}\right]$ acetate incorporated into the lipid fraction of liver from control animals was $19.0 \pm 1.6$ per cent of total incorporation compared to $13.7 \pm 1.6$ per cent for treated animals $(\mathrm{P}<0.001)$. Thus, the administration of compound 1 to rats inhibited acetate incorporation into lipids in both plasma and liver by almost the same extent (approximately 70 per cent of control) as it caused the depression of plasma cholesterol (Table 1).

Table 2 also shows the distribution of radioactivity among individual lipid classes in both liver and blood plasma. The incorporation of $\left[{ }^{14} \mathrm{C}\right]$ acetate into not only cholesterol and cholesterol ester but also into all other lipid classes, such as phospholipid, free fatty acid + diglyceride and triglyceride, was depressed by compound 1 administration. These results suggest that compound 1 or its metabolite(s) could not be an inhibitor of a single lipid biosynthetic pathway.

To elucidate the site of inhibitory action of compound 1 on $\left[{ }^{14} \mathrm{C}\right]$ acetate incorporation into glycerolipids (Table 2), both phospholipid and triglyceride fractions from the liver specimens were hydrolyzed to glycerol plus free fatty acids. Radioactivity in each fraction was determined. In phospholipids, the amount of label incorporated into the fatty acid moieties was $92.3 \pm 3.8$ per cent for the samples from the five control rats compared to $79.9 \pm 7.9$ per cent for samples from the five treated rats. Combining these data with the corresponding total dpm incorporated into phospholipids (Table 2), it was calculated that there was a 40 per cent inhibition of $\left[{ }^{14} \mathrm{C}\right]$ acetate incorporation into the fatty acid moieties in the compound 1-treated animals. In contrast, the incorporation of $\left[{ }^{14} \mathrm{C}\right]$ acetate into the glycerol-3-phosphate moiety increased by 80 per cent in the compound 1-treated animals. Likewise in triglycerides, $69.3 \pm 4.2$ per cent of the label was found in the fatty acid moieties from control animals compared to $60.5 \pm 5.1 \mathrm{per}$ cent from treated animals. These figures represent a 21 per cent reduction in the $\left[{ }^{14} \mathrm{C}\right]$ acetate labeling of the fatty acids and a 16 per cent increase in the labeling of the glycerol moiety. Apparently, the inhibition of fatty acid synthesis (Table 2 and above) by compound 1 caused an increased availability of $\left[{ }^{14} \mathrm{C}\right]$ acetyl $\mathrm{CoA}$ for the tricarboxylic acid

Table 1 . Compound 1 pretreatment of rats*

\begin{tabular}{|c|c|c|c|c|c|}
\hline \multirow[b]{2}{*}{$\begin{array}{l}\text { Animal } \\
\text { group }\end{array}$} & \multirow[b]{2}{*}{$\begin{array}{c}\text { Body } \\
\text { Wt } \\
(\mathrm{g})\end{array}$} & \multirow[b]{2}{*}{$\begin{array}{l}\text { Plasma } \\
\text { cholesterol } \\
(\mathrm{mg} / \mathrm{dl})\end{array}$} & \multirow[b]{2}{*}{$\begin{array}{c}\text { Liver } \\
\text { wt } \\
(\mathrm{g})\end{array}$} & \multicolumn{2}{|c|}{$\left[2{ }^{14} \mathrm{C}\right]$ Acetate incorporation into } \\
\hline & & & & $\begin{array}{c}\text { Liver } \\
(\mathrm{dpm} / \mathrm{mg})\end{array}$ & $\begin{array}{c}\text { Plasma } \\
\left([\mathrm{dpm} / \mathrm{ml}] \times 10^{-3}\right)\end{array}$ \\
\hline Control & $181 \pm 3 \dagger$ & $72 \pm 5$ & $8.0 \pm 0.5$ & $181 \pm 18$ & $72 \pm 6$ \\
\hline $\begin{array}{l}\text { Treated } \\
\text { \% Controll| }\end{array}$ & $\begin{array}{c}172 \pm 4 \neq \\
95\end{array}$ & $53 \pm 7 \S$ & $\begin{array}{c}7.5 \pm 0.5 \\
94\end{array}$ & $\begin{array}{c}189 \pm 30 \\
104\end{array}$ & $\begin{array}{c}68 \pm 15 \\
94\end{array}$ \\
\hline
\end{tabular}

${ }^{*}$ Groups of five rats each received vehicle alone or $25 \mathrm{mg} \cdot \mathrm{kg}^{-1} \cdot \mathrm{day}^{-1}$ of compound 1 for 4 consecutive days. Twenty-five hours after the last dose and $1 \mathrm{hr}$ after the administration of [2${ }^{14} \mathrm{Clacetate}(100 \mu \mathrm{Ci} / \mathrm{kg})$, blood was collected by cardiac puncture, and livers were excised. Variables were measured as described in the text.

$\dagger$ Means from five replicate observations or assays expressed \pm S.D.

$\ddagger$ Value from testing the identity of data from control and treated animals by Student's t-test, $\mathrm{P}<$ 0.01 .

$\S \mathrm{P}<0.005$.

$\|$ Treated value as per cent of control value. 
Table 2. Effect of compound 1 on the incorporation of $\left[{ }^{14} \mathrm{C}\right]$ acetate into lipids from plasma and liver*

\begin{tabular}{lcccccc}
\hline & \multicolumn{5}{c}{ Plasma lipid fraction (dpm/ml plasma) } \\
\cline { 2 - 7 } $\begin{array}{l}\text { Animal } \\
\text { group }\end{array}$ & $\begin{array}{c}\text { Total lipid } \\
\text { extract }\end{array}$ & Phospholipids & $\begin{array}{c}\text { Free fatty acids } \\
+ \\
\text { diglycerides }\end{array}$ & Triglycerides & $\begin{array}{c}\text { Free } \\
\text { cholesterol }\end{array}$ & $\begin{array}{c}\text { Esterified } \\
\text { cholesterol }\end{array}$ \\
\hline Control & $2610 \pm 650$ & $286 \pm 60$ & $102 \pm 29$ & $1354 \pm 470$ & $367 \pm 113$ & $195 \pm 60$ \\
Treated & $1780 \pm 860$ & $205 \pm 59 \dagger$ & $77 \pm 23$ & $949 \pm 700$ & $202 \pm 66 \dagger$ & $130 \pm 60 \dagger$ \\
$\%$ Control & 68 & 72 & 76 & 70 & 55 & 67 \\
& & & Liver lipid fraction & $(\mathrm{dpm} / \mathrm{mg}$ liver) & & \\
Control & $34 \pm 5$ & $14.2 \pm 2.4$ & $0.49 \pm 0.24$ & $7.9 \pm 0.78$ & $3.3 \pm 1.1$ & $0.44 \pm 0.24$ \\
Treated & $26 \pm 4 \ddagger$ & $9.9 \pm 1.8 \S$ & $0.27 \pm 0.03$ & $7.1 \pm 0.85$ & $2.3 \pm 0.9$ & $0.29 \pm 0.09$ \\
\% Control & 76 & 70 & 55 & 90 & 70 & 66 \\
\hline
\end{tabular}

* Plasma and liver specimens from control and treated rats described in Table 1 were extracted and separated into the selected lipid fractions. Separation techniques and measurement of incorporated label were performed as described in the text. Data are presented as detailed in the legend to Table 1.

$+\mathbf{P}<0.05$.

$\$ \mathrm{P}<0.01$.

$\S \mathrm{P}<0.005$

Table 3. Effect of compound 1 on lipid composition of plasma and liver*

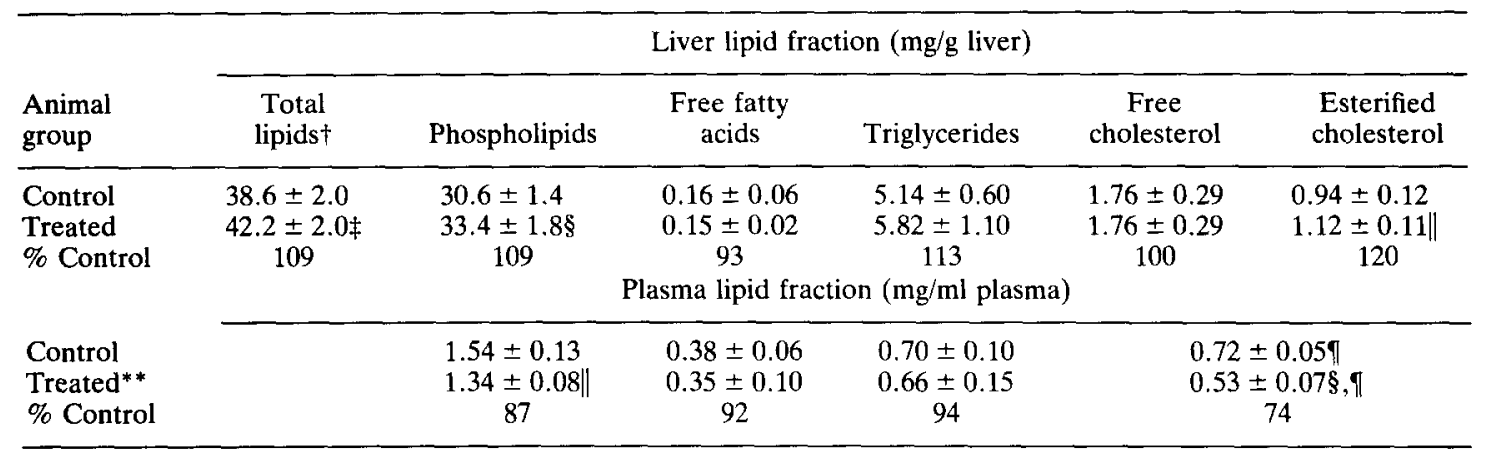

* Plasma and liver specimens from control and treated rats described in Table 1 were extracted, separated into the selected lipid fractions, and assayed as described in the text. Data are presented as detailed in the legend to Table 1.

$\dagger$ Sum of the next five columns.

$\mp \mathrm{P}<0.01$.

$\S P<0.005$.

$\| \mathrm{P}<0.05$.

II Assay for free plus esterified cholesterol.

** Specimens available from only four rats.

cycle and other pathways leading to an increased labeling of the glycerol moiety of these glycerolipids. In a similar vein, an increase in the biosynthesis of $\mathrm{COA}$ has been observed in the liver of rats treated with the hypolipidemic drug clofibrate [10].

In comparison to the inhibition of $\left[{ }^{14} \mathrm{C}\right]$ acetate incorporation into fatty acids and cholesterol, the lipid content of the liver increased slightly in compound 1-treated rats owing to an increase in phospholipids. There also was a small but statistically significant increase in cholesterol esters (Table 3 ). In contrast, plasma specimens from treated animals had lower levels of both total cholesterol and phospholipids. The fact that both phospholipids and cho-

* Present address: Medical Research Institute, Tokyo Medical and Dental University, No. 3-10, 2-Chome, Kandasurugadai, Chiyoda-Ku, Tokyo 101, Japan.

$\dagger$ To whom correspondence should be addressed at The University of Michigan.

lesterol esters accumulated slightly in liver suggests that compound 1 also has a minor inhibitory action on lipoprotein formation in liver or its release into plasma.

From these studies, we have concluded that the serum cholesterol-lowering activity of compound 1 in rats was a result of inhibition of hepatic fatty acid and cholesterol biosynthesis. The inhibitory activities occurred at a step subsequent to the formation of acetyl CoA.

Acknowledgement-This work was supported by Public Health Service Grant GM 19815 from the National Institutes of Health, Bethesda, MD.

\section{Laboratory of Medicinal} Chemistry

College of Pharmacy,

The University of Michigan, Ann Arbor, MI 48109, U.S.A.
Kozo IsHIDATE* JOHN C. DRACH ${ }^{\dagger}$ JOSEPH E. SINSHEIMER JOSEPH H. BURCKHALTER 


\section{REFERENCES}

1. J. H. Burckhalter, W. D. Dixon, M. L. Black, R. D. Westland, L. M. Werbel, H. A. DeWald, J. R. Dice, G. Rodney and D. H. Kaump, J. med. Chem. 10, 565 (1967).

2. R. J. Franey and E. Amador, Clinica chim. Acta 21, 255 (1968).

3. J. Folch, M. Lees and G. H. Sloane-Stanley, J. biol. Chem. 226, 497 (1957)

4. N. Tuna and H. K. Mangold, in Evolution of the Arteriosclerotic Plaque (Ed. R. J. Jones), p. 83 University of Chicago Press, Chicago (1963).
5. V. P. Skipski, A. F. Smolowe, R. C. Sullivan and M. Barclay, Biochim. biophys. Acta 106, 386 (1965).

6. D. J. Hanahan and J. N. Olley, J. biol. Chem. 231, 813 (1958).

7. W. G. Duncombe, Biochem. J. 88, 7 (1963).

8. G. Rouser, A. N. Siakotos and S. Fleischer, Lipids 1, 85 (1966).

9. J. E. Sinsheimer, E. Van den Eeckhout, L. E. Hewitt, Y. Kido, D. R. Wade, D. W. Hansen, Jr., J. C. Drach and J. H. Burckhalter, J. med. Chem. 19, 647 (1976). 10. S. Skrede and O. Halvorsen, Eur. J. Biochem. 98,223 (1979).

\section{The effect of ethanol on glycyl-prolyl dipeptidyl-aminopeptidase activity in the rat pancreas and liver}

(Received 24 March 1980; accepted 4 July 1980)

It is well documented that chronic pancreatitis is frequently associated with ethanol abuse. However, the pathogenetic mechanism whereby excessive intake of ethanol results in the injury of pancreas, eventually leading to pancreatic fibrosis, remains yet to be elucidated [1].

Attention has recently been given to the role of $X$-prolyl dipeptidyl-aminopeptidase, particularly of glycyl-prolyl dipeptidyl-aminopeptidase which is mainly localized in the microsomal fraction of the cell [2], in a series of pathophysiological states concerning collagen metabolism $[3,4]$. The present experiment was designed to investigate the change of glycyl-prolyl dipeptidyl-aminopeptidase activity in the rat pancreas and liver under the condition of chronic ethanol feeding with a nutritionally adequate liquid diet.

A total of 17 male Wistar rats, with an average body weight of $214 \mathrm{~g}$ at the beginning of the experiment, were divided into two groups. All animals received the liquid diet (Oriental Kobo Co., Tokyo, Japan) according to DeCarli and Lieber [5] for 4 weeks. The diet supplies 18 per cent of the total calories as protein, 35 per cent as lipid, 11 per cent as carbohydrate and 36 per cent either as additional carbohydrate (Control group) or as isocaloric ethanol (Ethanol group).

At the end of the experiment, two pairs of animals were killed by exsanguination from the abdominal aorta after an overnight fast. The pancreas and liver were immediately removed, homogenized in $10 \mathrm{vol} .0 .25 \mathrm{M}$ sucrose and centrifuged at $15,000 \mathrm{~g}$ for $15 \mathrm{~min}$. the supernatant of the homogenate and the serum were taken for enzyme assay. Glycyl-prolyl dipeptidyl-aminopeptidase activity was determined by the method of Nagatsu et al. [4], using glycylproline p-nitroanilide (Protein Research Foundation, Osaka, Japan) as substrate. Amylase activity was measured with Phadebas amylase test (Pharmacia, Sweden). Both enzymatic activities have been known not to be inhibited in sucrose solution $[2,6]$.

As expressed in Table 1, amylase activities both in serum and pancreas homogenate were significantly lower in the ethanol group than in the control group. Sardesai and Orten [7] have demonstrated a decrease in protein synthesis by the pancreas after chronic ethanol consumption in rats, although under the short-term administration of ethanol the incorporation of labelled amino acid into various sub cellular fractions of the pancreas remained unchanged [8]. The present study revealed that amylase activities in pancreas and serum were significantly decreased after 4 weeks of ethanol feeding, indicating a disturbed synthesis of pancreatic enzyme.

The pancreatic content of glycyl-prolyl dipeptidyl-aminopeptidase, on the other hand, was markedly elevated after ethanol treatment, whereas activity of the enzyme in either serum or liver tissue remained unaffected (Table 1). Figure 1 shows the relationship between amylase and glycyl-prolyl dipeptidyl-aminopeptidase activities in the pancreas. There was a significant $(P<0.01)$ inverse correlation. The rise of pancreatic glycyl-prolyl dipeptidylaminopeptidase activity, therefore, seemed to reflect the process linked closely with acinar impairment.

Glycyl-prolyl dipeptidyl-aminopeptidase is regarded as a kind of collagen-peptidase, presumably participating in collagen degradation, since it preferentially liberates dipeptide-fragment glycylproline which is contained abundantly in collagen molecule [4]. A rise of its activity, in fact, has been reported in the experimental granuloma, where collagen turns over rapidly [3]. The findings obtained here,

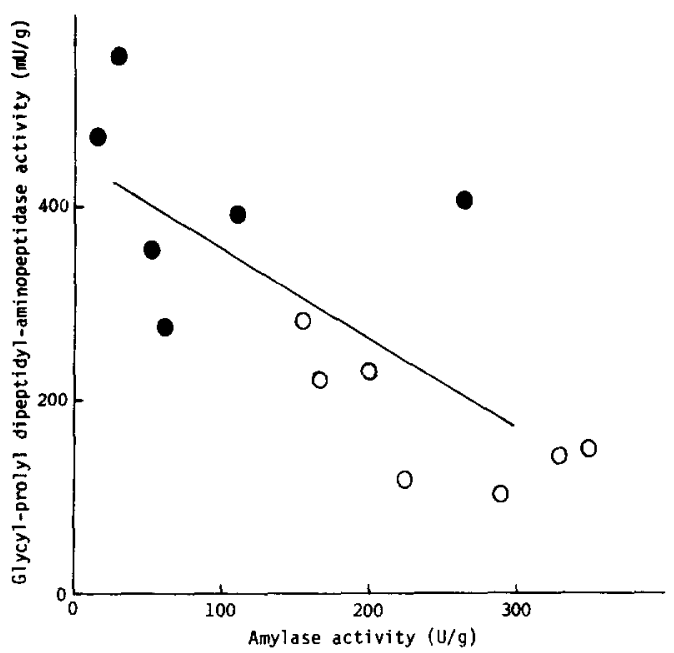

Fig. 1. Relationship between glycyl-prolyl dipeptidyl-aminopeptidase and amylase activities in pancreas. $O$ : Control; : ethanol. $r=-0.73$. P $<0.01 . y=-0.92 x+447$. 